\title{
Effect of Simultaneous Addition of Mn and Mischmetal on the High Temperature Deformation Behavior of AZ61 Magnesium Alloy
}

\author{
Xiaochao $\mathrm{Wu}^{1,2}$, Mao Chen ${ }^{1}$, Ruixiao $\mathrm{Qu}^{1}$, Qingkui $\mathrm{Li}^{1,2,{ }^{*}}$ and Shaokang Guan ${ }^{1,2}$ \\ ${ }^{1}$ College of Materials Science and Engineering, Zhengzhou University, Zhengzhou 450001, China \\ ${ }^{2}$ Key Lab for Advanced Magnesium Alloys of Henan Province, Zhengzhou 450003, China
}

\begin{abstract}
The high temperature deformation behavior of a modified AZ61 magnesium alloy was investigated by means of an isothermal compression test on a Gleeble-2000D elevated temperature simulation tester at strain rates of $0.1 \mathrm{~s}^{-1}$ and $1 \mathrm{~s}^{-1}$ and deformation temperatures of $523 \mathrm{~K}$, $623 \mathrm{~K}$ and $723 \mathrm{~K}$. The microstructure evolutions and second phases of the experimental alloys were analyzed. Compared to the conventional alloy, the modified specimen shows a higher degree of dynamic softening and a lower deformation resistance. The improved deformability becomes more apparent when temperature decreases or strain rate increases, and it is attributed to a great reduction in $\mathrm{Mg}_{17} \mathrm{Al}_{12}$ phase and to the formation of $\mathrm{Al}_{4} \mathrm{RE}$ and $\mathrm{Al}_{10} \mathrm{RE}_{2} \mathrm{Mn}_{7}$ phases caused by the simultaneous addition of $\mathrm{Mn}$ and mischmetal. [doi:10.2320/matertrans.M2016445]
\end{abstract}

(Received December 13, 2016; Accepted April 26, 2017; Published June 25, 2017)

Keywords: AZ61 magnesium alloy, simultaneous addition of manganese and mischmetal, true stress-true strain curves, dynamic softening, second phases

\section{Introduction}

Magnesium alloys have broad applications in electronics, and in the automotive and aerospace industries for weight reduction and high fuel efficiency ${ }^{1)}$. In recent years, magnesium alloys are also attracting increasing attentions as biomedical materials due to their excellent degradability ${ }^{2}$. With a broader application of magnesium alloys, the demand for complex-shaped extruded magnesium is growing. However, owing to intrinsic characteristics of the hexagonal close-packed lattice structure, magnesium alloys have poor formability and limited ductility at room temperature ${ }^{3-6)}$. Therefore, forging of magnesium product is always performed at elevated temperature, whereby non-basal slips can be activated to enhance hot workability ${ }^{7)}$. However, even at an elevated temperature, the formability of magnesium alloys is not good, and leads to low extrusion efficiency. AZ61 alloy is a widely used wrought magnesium alloy because of its low cost and moderate properties. Many investigations have been carried out on its hot processing parameters and its deformation behavior ${ }^{8-13)}$. The combined effect of the rare earth elements (mischmetal, abbreviated as $\mathrm{Mm}$ ) and manganese $(\mathrm{Mn})$ on the deformation behaviors of AZ61 magnesium alloy has rarely been reported.

In previous studies conducted by our group ${ }^{14)}$, the chemical content of $\mathrm{Mn}$ and $\mathrm{Mm}$ in AZ61 alloy were co-modified in order to improve workability. The composition range of $\mathrm{Mn}$ and $\mathrm{Mm}$ was $0.3 \sim 0.8 \%$ and $0.4 \sim 1.0 \%$ (mass fraction), respectively. Based on earlier results, a Mn-RE co-modified specimen and a standard AZ61 alloy were prepared for this research. The true stress-true strain curves at different deformation conditions of the alloys were plotted to investigate the deformation behavior. The microstructure evolutions and second phases of the experimental alloys were analyzed to reveal the influence mechanisms of simultaneous addition of $\mathrm{Mm}$ and $\mathrm{Mn}$ on the deformation behavior.

*Corresponding author, E-mail: qkli491@ @zu.edu.cn

\section{Experimental Procedure}

The chemical compositions of the two alloys involved in the experiment are listed in Table 1. Mn was added in the form of Mg-Mn master alloy, while $\mathrm{Mm}$ was added in form of cerium-rich $\mathrm{Mm}$ (Ce 50.20\%, La 26.67\%, Nd 15.28\% and $\mathrm{Pr}$ $5.37 \%, 2.48 \%$ other rare earth elements).

The cast alloys were homogenized at $400^{\circ} \mathrm{C}$ for $10 \mathrm{~h}$ followed by cooling in air. Cylindrical specimens of $15 \mathrm{~mm}$ gauge length and $10 \mathrm{~mm}$ gauge diameter were machined from the homogenized ingots. Isothermal hot compression tests were conducted on a Gleeble-2000D thermal simulation machine at $523 \mathrm{~K}, 623 \mathrm{~K}$, and $723 \mathrm{~K}$, and at strain rates $0.1 \mathrm{~s}^{-1}$ and $1 \mathrm{~s}^{-1}$. Prior to compressing to a true strain of 0.9 , the specimens were heated to the deformation temperature at a rate of $10 \mathrm{~K} / \mathrm{s}$ and maintained at that temperature for a period of $180 \mathrm{~s}$. Graphite lubricant was used for reduction of friction between the press indenters and the specimens. After isothermal compression, the specimens were water quenched immediately in order to reserve the deformation microstructure. Microstructural observations were made on the longitudinal section of the hot-compressed specimens by using an Olympus H2-UMA optical microscope and a Philip-Quanta200 scanning electron microscope equipped with energy dispersive spectrometer (EDS). The etchant for the homogenized specimen was prepared by using picric acid, acetic acid, and ethanol. The etchant for the hot-compressed specimen was a mixture of acetic acid, nitric acid, and oxalic acid. The twin crystals and nucleation of dynamic recrystallization (DRX) were characterized by using a Tecnai-G2-F20 Transmission electron microscopy (TEM).

Table 1 Elemental composition of the experimental alloys (mass fraction).

\begin{tabular}{cccccccccc}
\hline Alloy & \multicolumn{8}{c}{ Elemental compositions (mass\%) } \\
No. & $\mathrm{Al}$ & $\mathrm{Zn}$ & $\mathrm{Mn}$ & $\mathrm{Fe}$ & $\mathrm{Si}$ & $\mathrm{Cu}$ & $\mathrm{Ni}$ & $\mathrm{Mm}$ & $\mathrm{Mg}$ \\
\hline I & 5.8354 & 0.8145 & 0.3004 & 0.0022 & 0.0067 & 0.0012 & 0.0005 & - & Bal. \\
II & 5.7874 & 0.8487 & 0.6807 & 0.0014 & 0.0075 & 0.0014 & 0.0006 & 0.67 & Bal. \\
\hline
\end{tabular}




\section{Results}

\subsection{True stress-true strain curves}

The true stress-true strain curves obtained from the isothermal compression tests are presented in Fig. 1. The measurements were repeated at different temperatures and at strain rates of $0.1 \mathrm{~s}^{-1}$ and $1 \mathrm{~s}^{-1}$. It can be observed that all of the curves exhibit the typical response of dynamic softening, characterized by a single peak followed by a steady-state flow ${ }^{15-17)}$. In the beginning of each compression test, the flow stress increases drastically with strain due to a dominating work hardening effect. At elevated strain, the rapidly accumulating stored energy provides a sufficient driving force for the dynamic recovery (DRV) and dynamic recrystallization (DRX). During this deformation period, there is a competition between work hardening and dynamic softening. The potential driving forces of DRV and DRX intensify with the increasing true strain. High deformation energy causes the nucleation and growth of new grains to be accelerated. DRV and DRX reorganize the dislocation structure and reduce its density, thereby reducing the stress in the compression process. As a result, the flow stress begins to decrease gradually after it reaches a peak value.

In Fig. 1, before the peaks appear, the true stress-true strain curves for alloy II exhibit more gradual slopes than for alloy I. This trend indicates that the work hardening in alloy $\mathrm{I}$ is more severe. In all 6 deformation conditions, $(523 \mathrm{~K}$ at $0.1 \mathrm{~s}^{-1}, 623 \mathrm{~K}$ at $0.1 \mathrm{~s}^{-1}, 723 \mathrm{~K}$ at $0.1 \mathrm{~s}^{-1}, 523 \mathrm{~K}$ at $1 \mathrm{~s}^{-1}$, $623 \mathrm{~K}$ at $1 \mathrm{~s}^{-1}$, and $723 \mathrm{~K}$ at $1 \mathrm{~s}^{-1}$ ), the true stress-true strain curves for alloy II demonstrate a lower deformation resistance than the curves for alloy I. This trend proves that alloy II has a better deform ability than alloy I for the given hot working conditions. Furthermore, the improved deformability of alloy II becomes more obvious when the deformation temperature reduces or when the strain rate increases. When the deformation conditions are $523 \mathrm{~K}$ at $1 \mathrm{~s}^{-1}$, the flow stresses of the two alloys demonstrate the greatest difference. On the contrary, when the deformation conditions are $723 \mathrm{~K}$ at $0.1 \mathrm{~s}^{-1}$, the true stress-true strain curves of the two alloys demonstrate the minimum difference. The differential between curve pairs representing the behavior of the two alloys reduces according to the sequence of deformation conditions $\left(523 \mathrm{~K}\right.$ at $1 \mathrm{~s}^{-1}, 523 \mathrm{~K}$ at $0.1 \mathrm{~s}^{-1}, 623 \mathrm{~K}$ at $1 \mathrm{~s}^{-1}, 623 \mathrm{~K}$ at $0.1 \mathrm{~s}^{-1}, 723 \mathrm{~K}$ at $1 \mathrm{~s}^{-1}$, and $723 \mathrm{~K}$ at $0.1 \mathrm{~s}^{-1}$ ). In order to better characterize the deformation behavior differential between alloy I and alloy II, the peak stresses and peak strain values were also extracted from raw data, and shown in Table 2 and Table 3.

As expected, the deformation resistance decreases when the temperature increases, and increases when the strain rate increases ${ }^{18)}$. Table 2 clearly demonstrates that the changes in peak stress for both alloys conform to this rule. Table 2 also reveals that the variation of the peak stress in alloy II is not as great as in alloy I when the deformation temperature changes. This observation reveals that the deformation behavior of alloy I is more sensitive to temperature changes than in alloy II. In addition, when the strain rate is changed, the variability of peak stress in alloy II is not as great as in alloy I. This is due to the fact that the microstructure of alloy II has a better coordination deformation capability than the microstructure of alloy I.

Table 3 shows that alloy II almost always exhibits lower peak strain values than alloy I in the various deformation conditions. Under the particular deformation conditions of $523 \mathrm{~K}$ at $1 \mathrm{~s}^{-1}$, alloy II reaches a significantly lower strain value than alloy I. In a typical DRX (dynamic recrystallization), the true stress-true strain curve descends after the peak because of the effects of dynamic softening which exceed the effects of work-hardening ${ }^{17)}$. Thus, compared to the corresponding curves of alloy I, the dynamic softening that overcomes work-hardening occurs earlier in alloy II. This indicates that alloy II has a better deformability.

Table 2 Peak stress values of isothermal compression tests in alloys I and II (MPa).

\begin{tabular}{ccccccc}
\hline & \multicolumn{3}{c}{$0.1 \mathrm{~s}^{-1}$} & \multicolumn{3}{c}{$1 \mathrm{~s}^{-1}$} \\
\cline { 2 - 7 } & $523 \mathrm{~K}$ & $623 \mathrm{~K}$ & $723 \mathrm{~K}$ & $523 \mathrm{~K}$ & $623 \mathrm{~K}$ & $723 \mathrm{~K}$ \\
\hline Alloy I & 158.1 & 93.9 & 61.1 & 173.2 & 112.5 & 78.2 \\
\hline Alloy II & 138.2 & 87.4 & 59.7 & 152.5 & 98.1 & 74.7 \\
\hline
\end{tabular}

Table 3 Peak strain values of isothermal compression tests in alloys I and II.

\begin{tabular}{ccccccc}
\hline & \multicolumn{3}{c}{$0.1 \mathrm{~s}^{-1}$} & \multicolumn{3}{c}{$1 \mathrm{~s}^{-1}$} \\
\cline { 2 - 7 } & $523 \mathrm{~K}$ & $623 \mathrm{~K}$ & $723 \mathrm{~K}$ & $523 \mathrm{~K}$ & $623 \mathrm{~K}$ & $723 \mathrm{~K}$ \\
\hline Alloy I & 0.1995 & 0.1439 & 0.1271 & 0.2593 & 0.2097 & 0.1859 \\
\hline Alloy II & 0.1858 & 0.1473 & 0.1355 & 0.2088 & 0.1898 & 0.1901 \\
\hline
\end{tabular}
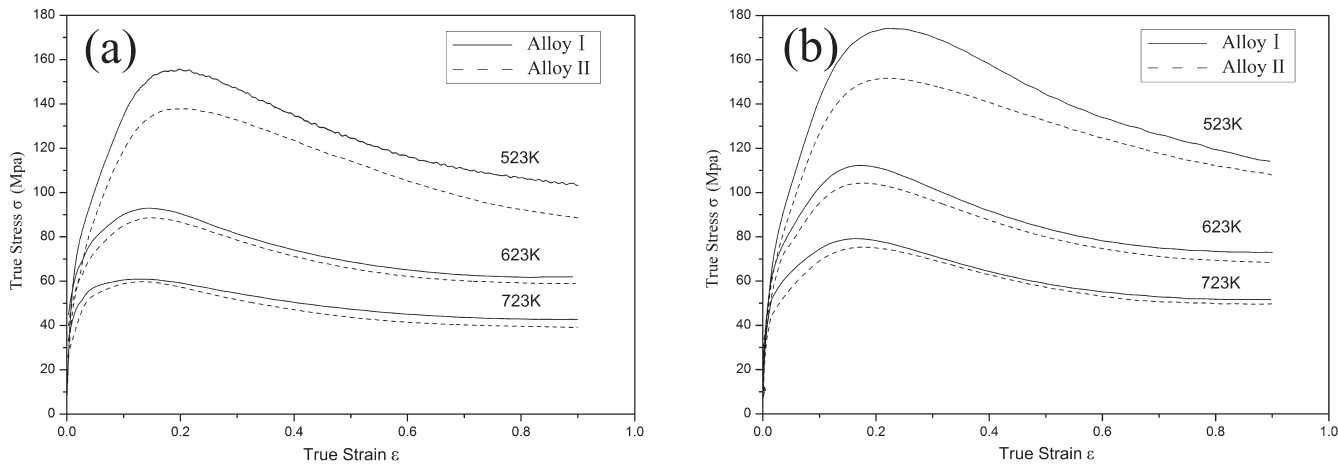

Fig. 1 True stress-true strain curves of experimental alloys at different strain rates and temperatures: (a) $\dot{\varepsilon}=0.1 \mathrm{~s}^{-1}$, (b) $\dot{\varepsilon}=1 \mathrm{~s}^{-1}$ 


\subsection{Microstructure evolution}

Microstructure evolution during the isothermal compression was investigated at the deformation temperatures of $523 \mathrm{~K}$ and $623 \mathrm{~K}$ and $1 \mathrm{~s}^{-1}$ strain rate. Specimens with three strain increments $(0.1,0.16$, and 0.3$)$ were prepared and their microstructures were preserved by water-cooling. For AZ series magnesium alloys, $673 \mathrm{~K}$ is an acceptable heat treatment temperature. The grains of the specimens will not coarsen at compression temperatures of $523 \mathrm{~K}, 623 \mathrm{~K}$ and $723 \mathrm{~K}$.

Figures 2(a), (c), and (e) show the microstructure evolution in alloy $\mathrm{I}$ at the deformation conditions of $523 \mathrm{~K}$ and $1 \mathrm{~s}^{-1}$ during the three progressive strain levels. Figures 2(b), (d), and (f) present the corresponding evolutions in alloy II. Comparing Figs. 2(a) and (b) it can be observed that crystal twinning occurs earlier in alloy II. When the strain is 0.1 , twinning can be observed in alloy II, but not in alloy I. The twin crystals can be clearly seen in the specimen made from alloy II by using TEM. This is illustrated in Fig. 3. Figure 2(c) shows that some twin crystals can be found in alloy I when the strain increases to 0.16. In Fig. 2(d), which shows the microstructure in alloy II, not only twinning can be observed, but also some small recrystallized grains. When the strain is 0.3 , the recrystallized grains and twinning can be observed in both alloy I and alloy II as shown in Figs. 2(e) and (f), respectively.
Furthermore, recrystallization is more pronounced in alloy II than in alloy I. Thus, it can be inferred that the simultaneous addition of $\mathrm{Mn}$ and $\mathrm{Mm}$ can promote the occurrence of twinning and recrystallization at the deformation conditions of $523 \mathrm{~K}$ and $1 \mathrm{~s}^{-1}$.

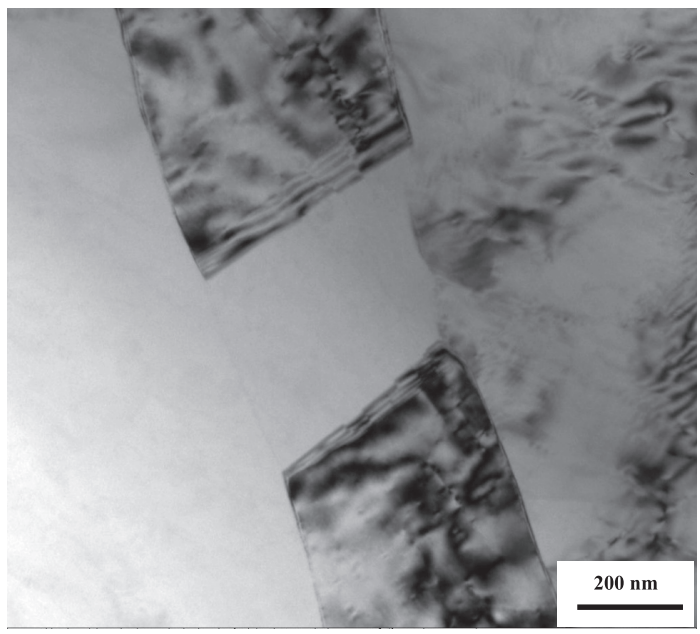

Fig. 3 Twin crystal observed in alloy II strained to 0.1 at $523 \mathrm{~K}$ and a strain rate of $1 \mathrm{~s}^{-1}$

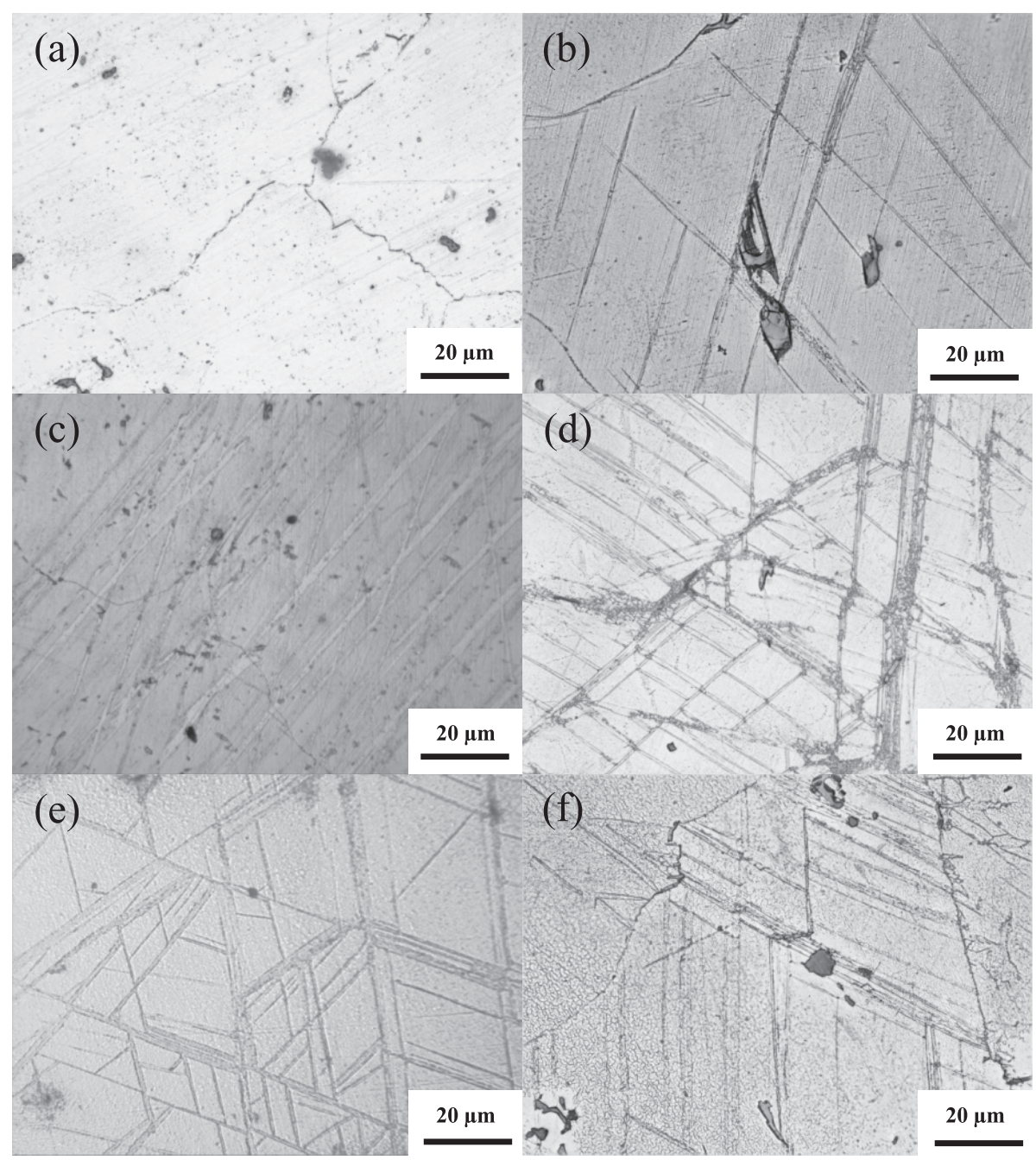

Fig. 2 Microstructure evolutions of alloys deformed at $523 \mathrm{~K}$ with a strain rate of $1 \mathrm{~s}^{-1}$ : (a) $\varepsilon=0.1$, alloy I, (b) $\varepsilon=0.1$, alloy II, (c) $\varepsilon=0.16$, alloy I, (d) $\varepsilon=$ 0.16 , alloy II, (e) $\varepsilon=0.3$, alloy I, (f) $\varepsilon=0.3$, alloy II. 


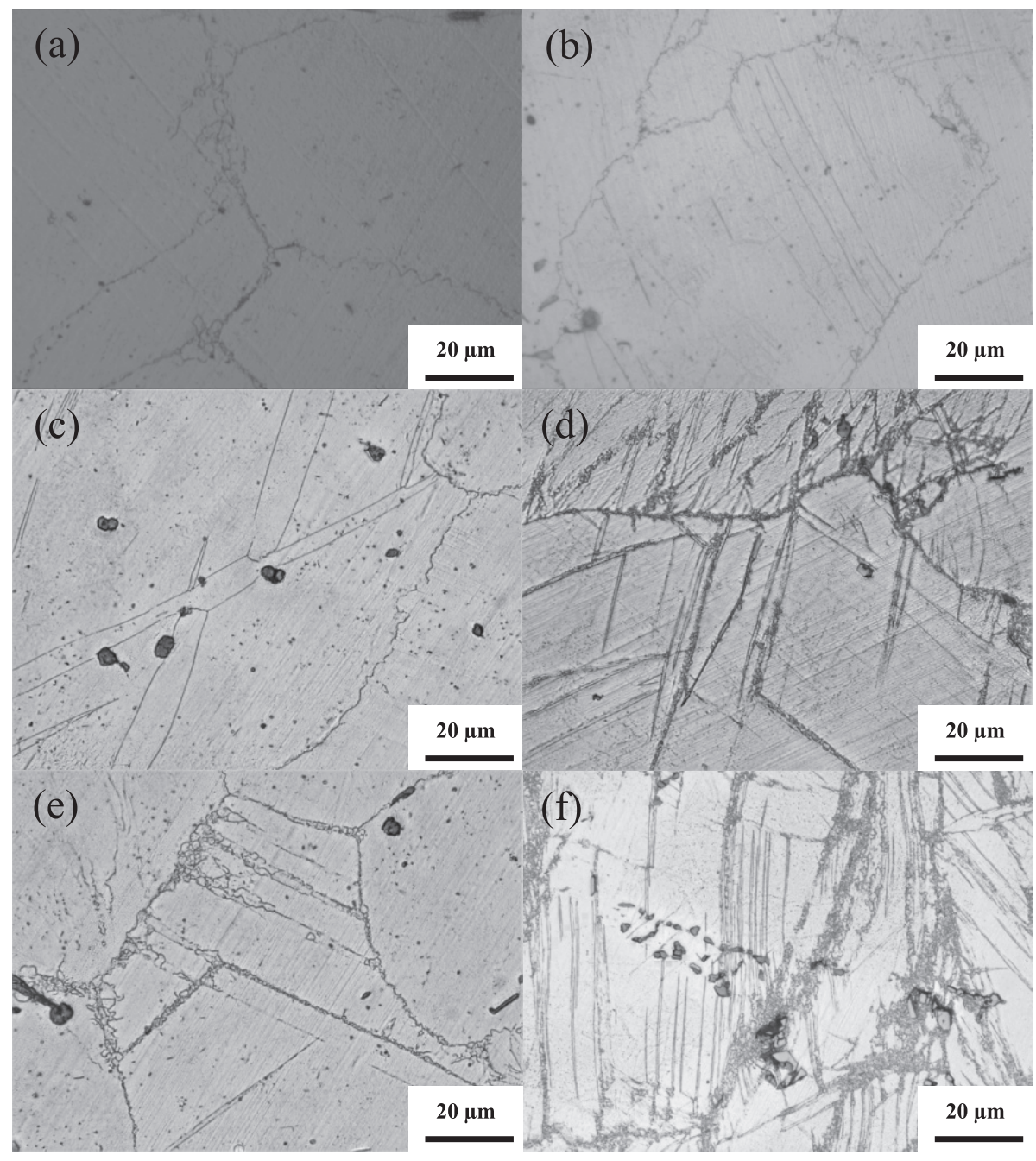

Fig. 4 Microstructure evolutions of alloys deformed at $623 \mathrm{~K}$ with a strain rate of $1 \mathrm{~s}^{-1}$ : (a) $\varepsilon=0.1$, alloy I, (b) $\varepsilon=0.1$, alloy II, (c) $\varepsilon=0.16$, alloy I, (d) $\varepsilon=$ 0.16 , alloy II, (e) $\varepsilon=0.3$, alloy I, (f) $\varepsilon=0.3$, alloy II.

The microstructure evolution in the experimental specimens at the deformation conditions of $623 \mathrm{~K}$ and $1 \mathrm{~s}^{-1}$ was also analyzed. Figures $4(\mathrm{a}),(\mathrm{c})$, and (e) present the microstructures in alloy I at strains $0.1,0.16$, and 0.3 , respectively. Figures 4(b), (d), and (f) present the corresponding microstructures in alloy II. As in Fig. 2, Fig. 4 indicates that crystal twinning and dynamic recrystallization appear earlier in alloy II than in alloy I.

From microstructure evolution analysis during deformation processing, it is can be inferred that the simultaneous addition of $\mathrm{Mn}$ and $\mathrm{Mm}$ is beneficial to the twinning formation and to the dynamic recrystallization of AZ61 magnesium alloy.

\section{Discussion}

To further elucidate the driving mechanisms of the evolution phenomenon encountered, the microstructures of the specimens were investigated further.

The initial microstructures of as-homogenized specimens are shown in Fig. 5. Compared to alloy I, grains in alloy II are significantly smaller. Considering that compression was performed at the elevated temperature $(523 \mathrm{~K}, 623 \mathrm{~K}, 723 \mathrm{~K})$, deformation is expected to take place at grain boundaries

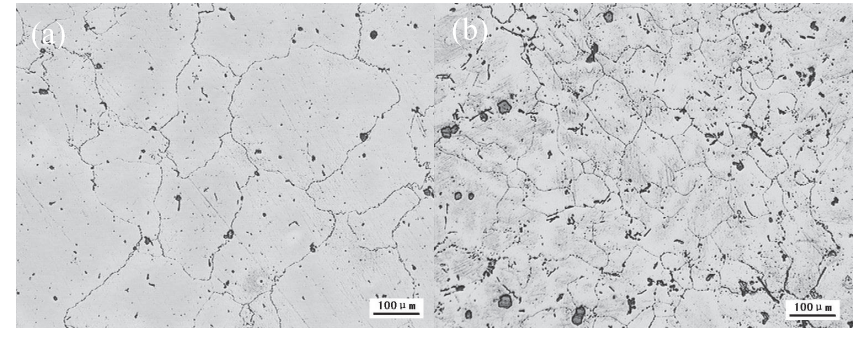

Fig. 5 Microstructure of homogenized specimens: (a) alloy I, (b) alloy II.

preferentially rather than in the grain interior ${ }^{19)}$. In addition, the increase in number of grain boundaries could also provide a greater number of interfaces to benefit to the nucleation of dynamic recrystallization during the hot deformation process. It is also helpful in improving the deformability of the specimens.

Before the isothermal compression was performed, the specimens were homogenized in order to force the $\mathrm{Mg}_{17} \mathrm{Al}_{12}$ to dissolve into the matrix. Since solid solution strengthening can improve the deformation resistance, the initial microstructures of the as-cast alloys were also analyzed and shown in Fig. 6. It can be observed that the amount of the reticular 
$\mathrm{Mg}_{17} \mathrm{Al}_{12}$ in alloy II is considerably reduced compared with that in alloy $\mathrm{I}$. When $\mathrm{Mg}_{17} \mathrm{Al}_{12}$ phase dissolved into the matrix, solid solution strengthening in alloy I should be more prominent than in alloy II. A weaker matrix could be another reason why alloy II shows a lower deformation resistance than alloy I.

In a further study, the second phases in alloy II were analyzed and shown in Fig. 7. According to SEM-EDS analysis, the second phases in alloy II are mainly composed of $\mathrm{Mg}_{17} \mathrm{Al}_{12}, \mathrm{Al}_{4} \mathrm{RE}$ and $\mathrm{Al}_{10} \mathrm{RE}_{2} \mathrm{Mn}_{7}$. After the addition of compound containing $0.7 \% \mathrm{RE}$ and $0.7 \% \mathrm{Mn}$ (mass fraction), the amount of $\mathrm{Mg}_{17} \mathrm{Al}_{12}$ phase decreased significantly. A relatively small needle-like $\mathrm{Al}_{4} \mathrm{RE}$ phase and a short-bar-shaped $\mathrm{Al}_{10} \mathrm{RE}_{2} \mathrm{Mn}_{7}$ phase appeared. These second phases were less than $40 \mu \mathrm{m}$ long. In order to reveal how the second phases affected the deformation behaviors of the specimens, their morphologies and distributions after the isothermal compression were also investigated. Figure 8(a) and (c) present the morphologies of $\mathrm{Al}_{10} \mathrm{RE}_{2} \mathrm{Mn}_{7}$ and $\mathrm{Al}_{4} \mathrm{RE}$ in the deformed

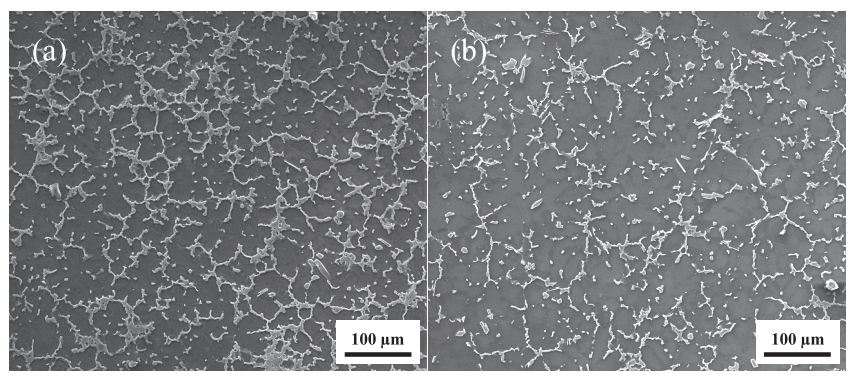

Fig. 6 Initial microstructure of as-cast specimens: (a) alloy I, (b) alloy II. specimens, while Fig. 8(b) and (d) illustrate their respective EDS patterns. It can be observed in Fig. 8 that both the needle-like $\mathrm{Al}_{4} \mathrm{RE}$ phase and shot-bar-shaped $\mathrm{Al}_{10} \mathrm{RE}_{2} \mathrm{Mn}_{7}$ phase are crushed into discontinuous pieces after the deformation of the matrix. The $\mathrm{Al}_{10} \mathrm{RE}_{2} \mathrm{Mn}_{7}$ phase, in particular, was crushed into many small pieces with a size smaller than 5 microns, and there is no obvious crack that can be observed in the matrix. It is considered to be an easily deformed and crispy phase that can't tear the matrix during the deformation.

In general, the second phases have a noticeable effect on work-hardening of metallic materials, but the deformation resistance in the modified AZ61 specimen is reduced because of the formation of $\mathrm{Al}_{10} \mathrm{RE}_{2} \mathrm{Mn}_{7}$ phase. Furthermore, the simultaneous addition of $\mathrm{Mn}$ and $\mathrm{Mm}$ can significantly reduce the amount of $\mathrm{Mg}_{17} \mathrm{Al}_{12}$ phase. Since solution strengthening is induced when $\mathrm{Mg}_{17} \mathrm{Al}_{12}$ dissolves into the matrix during homogenization processing, the deformation resistance in alloy II should be lower than in alloy I. This is attributed to the lower amount of $\mathrm{Mg}_{17} \mathrm{Al}_{12}$, and it is probably another reason why alloy II has a better deformability. As deformation progresses, $\mathrm{Al}_{4} \mathrm{RE}$ and $\mathrm{Al}_{10} \mathrm{RE}_{2} \mathrm{Mn}_{7}$ are crushed into discontinuous pieces and can impede the dislocation slip from forming a dislocation tangle. This is beneficial to dynamic recrystallization nucleation. Moreover, the crushed small pieces of second phase could provide more interfaces for the nucleation of dynamic recrystallization ${ }^{20)}$. This hypothesis can be confirmed by Fig. 9, in which several nucleated DRX grains can be observed around the second phase in alloy II subjected to a strain of 0.3 at $523 \mathrm{~K}$ and a strain rate of $1 \mathrm{~s}^{-1}$. Therefore, the simultaneous addition of $\mathrm{Mn}$ and $\mathrm{Mm}$ can promote the dynamic recrystallization in AZ61 magnesium alloy II.
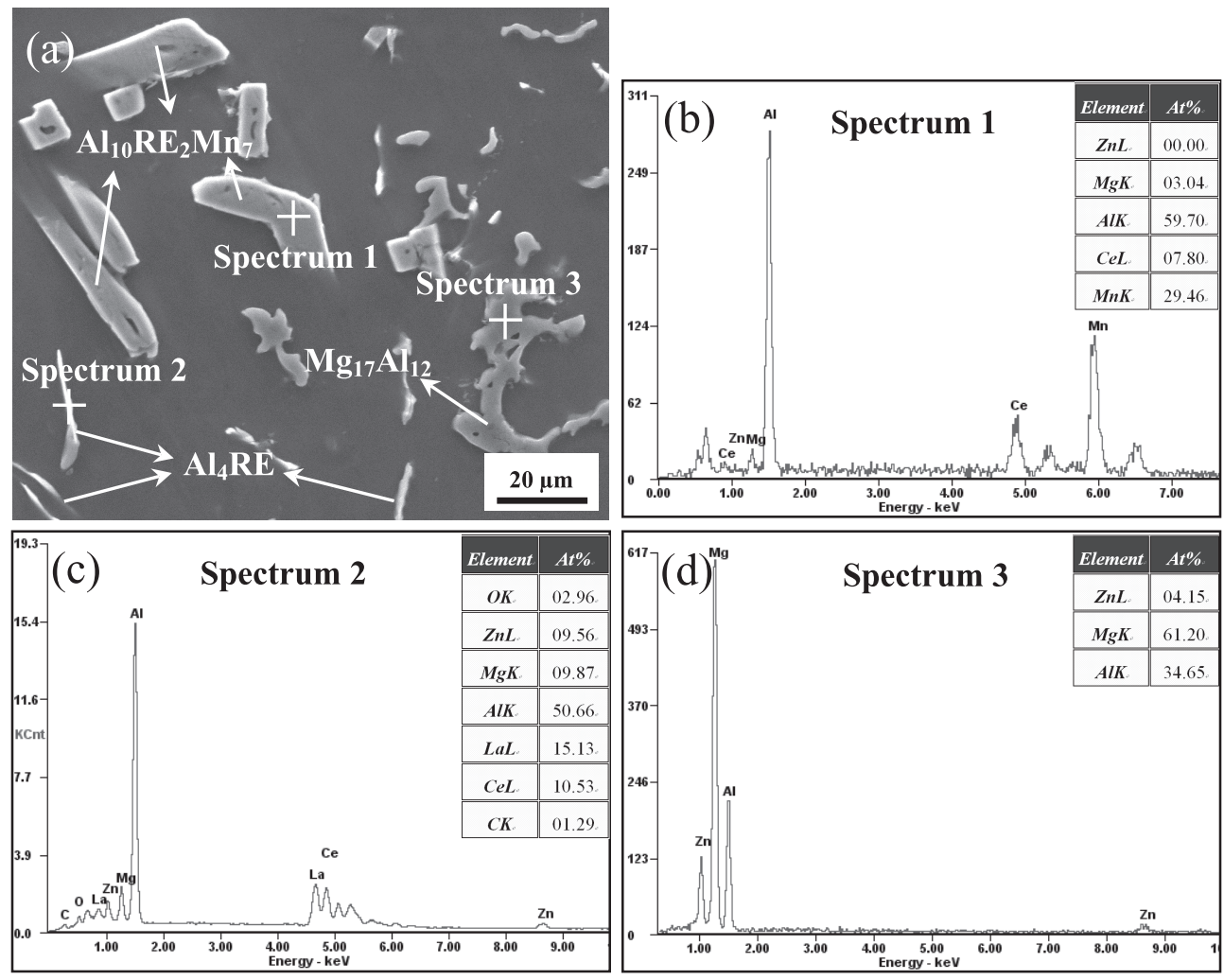

Fig. 7 Phase analysis of alloy II: (a) SEM image of the second phases in alloy II before isothermal compression, (b) EDS pattern of Al ${ }_{10} \mathrm{RE}_{2} \mathrm{Mn}_{7}$, (c) EDS pattern of $\mathrm{Al}_{4} \mathrm{RE}$, (d) EDS pattern of $\mathrm{Mg}_{17} \mathrm{Al}_{12}$. 

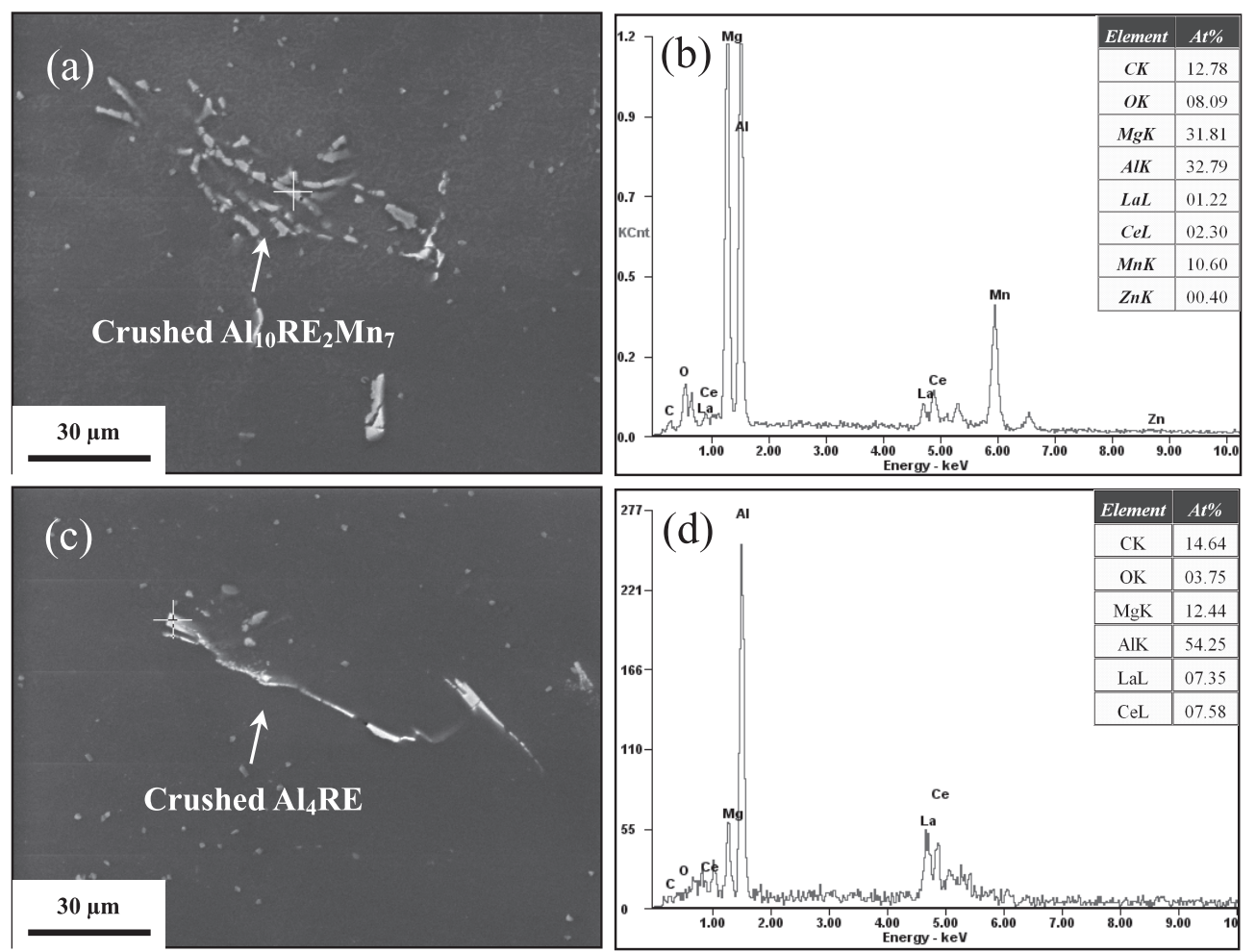

Fig. 8 Phase analysis of alloy II strained to 0.3 at $523 \mathrm{~K}$ and a strain rate of $1 \mathrm{~s}^{-1}$ : (a) SEM image of crushed $\mathrm{Al}_{10} \mathrm{RE}_{2} \mathrm{Mn}_{7}$ (b) EDS pattern of crushed $\mathrm{Al}_{10} \mathrm{RE}_{2} \mathrm{Mn}_{7}$ (c) SEM image of crushed $\mathrm{Al}_{4} \mathrm{RE}$ (d) EDS pattern of crushed $\mathrm{Al}_{4} \mathrm{RE}$.

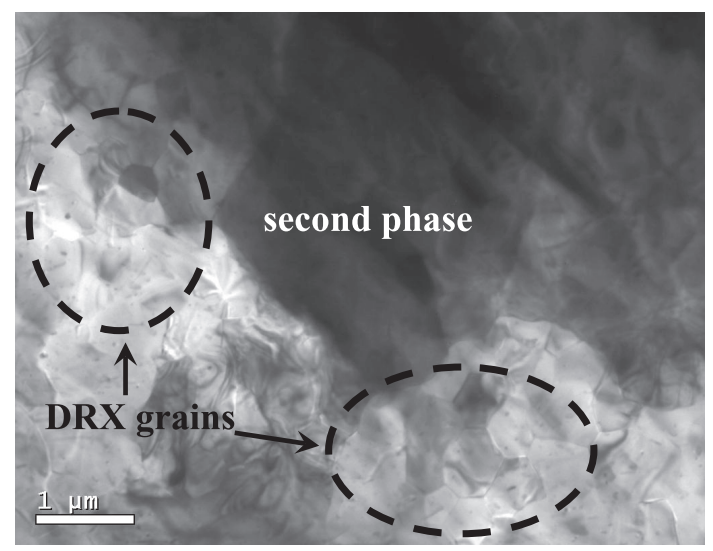

Fig. 9 Nucleated DRX grains located near the second phase in alloy II strained to 0.3 at $523 \mathrm{~K}$ and a strain rate of $1 \mathrm{~s}^{-1}$.

Attributed to the same reasoning is also the assertion that the Mn-Mm modified specimen (alloy II) is a better and more deformable material than alloy I.

\section{Conclusions}

In this paper, the effect of the simultaneous addition of Mn and $\mathrm{Mm}$ on the high temperature deformation behavior of AZ61 magnesium alloy was investigated. The true stress-true strain curves of the specimens were characterized at strain rates of $0.1 \mathrm{~s}^{-1}$ and $1 \mathrm{~s}^{-1}$ and at deformation temperatures of $523 \mathrm{~K}, 623 \mathrm{~K}$, and $723 \mathrm{~K}$. The microstructure evolutions and second phases of the experimental alloys were also analyzed to reveal the deformation mechanisms. The main conclusions can be summarized as follows:

(1) The simultaneous addition of $0.7 \% \mathrm{Mn}$ and $0.7 \% \mathrm{Mm}$ (mass fraction) improves the high temperature deformability of AZ61 magnesium alloy. The improvement is more pronounced at lower processing temperatures and at higher strain rates.

(2) Dynamic softening can be enhanced by Mn-Mm co-addition in AZ61 magnesium alloy. This leads to a decrease in deformation resistance.

(3) The simultaneous addition of $0.7 \% \mathrm{Mn}$ and $0.7 \% \mathrm{Mm}$ lead to a grain refinement in AZ61 magnesium alloy which is beneficial to the nucleation of dynamic recrystallization and deformability at elevated temperatures.

(4) The simultaneous addition of $0.7 \% \mathrm{Mn}$ and $0.7 \% \mathrm{Mm}$ not only reduces the amount of $\mathrm{Mg}_{17} \mathrm{Al}_{12}$ significantly but also forms small $\mathrm{Al}_{10} \mathrm{RE}_{2} \mathrm{Mn}_{7}$ and $\mathrm{Al}_{4} \mathrm{RE}$ phases. These phases can be crushed into small pieces during the deformation of the matrix. Their presence impedes dislocation and increases the number of interfaces beneficial to the nucleation of dynamic recrystallization.

\section{Acknowledgment}

Financial support from the National Natural Science Foundation of China under Grant No.51275484 is gratefully acknowledged.

\section{REFERENCES}

1) J. Zhang, Y.C. Dou, B.X. Zhang and X.D. Luo: Mater. Lett. 65 (2011) 944-947. 
2) C.Z. Zhang, S.J. Zhu, L.G. Wang, R.M. Guo, G.C. Yue and S.K. Guan: Mater. Des. 96 (2016) 54-62.

3) J. Zhang, W.G. Li, B.X. Zhang and Y.C. Dou: Mater. Sci. Eng. A 528 (2011) 4740-4746.

4) C. Fang, J. Zhang, A.L. Liao, S.Z. Xue, F.Q. Yuan and F.S. Pan: T. Nonferr. Metal. Soc. 20 (2010) 1841-1845.

5) Y.Q. Yang, B.C. Li and Z.M. Zhang: Mater. Sci. Eng. A 499 (2009) 238-241.

6) Y.B. Yang, F.C. Wang, C.W. Tan, Y.Y. Wu and H.N. Cai: T. Nonferr. Metal. Soc. 18 (2008) 1043-1046.

7) H.Y. Wu, J.C. Yang, J.H. Liao and F.J. Zhu: Mater. Sci. Eng. A 535 (2012) 68-75.

8) L.C. Tsao, Y.T. Huang and K.H. Fan: Mater. Des. 53 (2014) 865-869.

9) H. Miura, M. Ito, X. Yang and J.J. Jonas: Mater. Sci. Eng. A 538 (2012) 63-68.

10) H. Asgari, J.A. Szpunar and A.G. Odeshi: Mater. Des. 61 (2014) 26-34.

11) M.G. Jiang, H. Yan and R.S. Chen: Mater. Des. 87 (2015) 891-900.

12) Y. Xu, L.X. Hu, T.Q. Deng and L. Ye: Mater. Sci. Eng. A 559 (2013)
$528-533$.

13) Y. Xu, L.X. Hu and Y. Sun: J. Alloy. Compd. 580 (2013) 262-269.

14) Y.Y. Wan, Influence of $\mathrm{Mn}$ and RE on the microstructures and mechanical properties of AZ61A wrought magnesium alloy [D]. Zhengzhou: Zhengzhou University, 2011.

15) S. Spigarelli, M.E. Mehtedi, M. Cabibbo, E. Evangelista, J. Kaneko and V. Gartnerova: Mater. Sci. Eng. A 462 (2007) 197-201.

16) W. Qiu, E.H. Han and L. Liu: J. Mater. Sci. Technol. 25 (2009) 441444.

17) H.F. Huang, F. Jiang, J. Zhou, L.L. Wei, M.C. Zhong and X.T. Liu: J. Alloy. Compd. 644 (2015) 862-872.

18) Y.F. Xia, G.Z. Quan and J. Zhou: T. Nonferr. Metal. Soc. 20 (2010) s580-s583.

19) G.J. Zhang, S.Y. Long and F.H. Cao: Spec. Cast. Nonferr. Alloy. 29 (2009) 270-272.

20) A. Galiyev, R. Kaishev and G. Gottstein: Acta Mater. 49 (2001) 11991207. 